University of Nebraska - Lincoln

DigitalCommons@University of Nebraska - Lincoln

1999

\title{
Gender Differences in the Relationships among SES, Family History of Alcohol Disorders and Alcohol Dependence
}

\author{
Geoffrey M. Curran \\ University of Arkansas \\ Scott F. Stoltenberg \\ University of Nebraska-Lincoln, sstoltenberg2@unl.edu \\ Elizabeth M. Hill \\ University of Detroit-Mercy \\ Sharon A. Mudd \\ University of Michigan \\ Frederic C. Blow \\ University of Michigan \\ See next page for additional authors
}

Follow this and additional works at: https://digitalcommons.unl.edu/psychfacpub

Part of the Psychiatry and Psychology Commons

Curran, Geoffrey M.; Stoltenberg, Scott F.; Hill, Elizabeth M.; Mudd, Sharon A.; Blow, Frederic C.; and Zucker, Robert A., "Gender Differences in the Relationships among SES, Family History of Alcohol Disorders and Alcohol Dependence" (1999). Faculty Publications, Department of Psychology. 428.

https://digitalcommons.unl.edu/psychfacpub/428

This Article is brought to you for free and open access by the Psychology, Department of at DigitalCommons@University of Nebraska - Lincoln. It has been accepted for inclusion in Faculty Publications, Department of Psychology by an authorized administrator of DigitalCommons@University of Nebraska - Lincoln. 
Authors

Geoffrey M. Curran, Scott F. Stoltenberg, Elizabeth M. Hill, Sharon A. Mudd, Frederic C. Blow, and Robert A. Zucker 


\title{
Gender Differences in the Relationships among SES, Family History of Alcohol Disorders and Alcohol Dependence*
}

\author{
GEOFFREY M. CURRAN, PH.D., ${ }^{\dagger}$ SCOTT F. STOLTENBERG, PH.D., ${ }^{\dagger}$ ELIZABETH M. HILL, PH.D., ${ }^{\dagger}$ \\ SHARON A. MUDD, M.S., R.N., ${ }^{\dagger}$ FREDERIC C. BLOW, PH.D., ${ }^{\dagger}$ AND ROBERT A. ZUCKER, PH.D. ${ }^{\dagger}$
}

HSR\&D Center for Mental Healthcare \& Outcomes Research, Central Arkansas Veterans Healthcare System, 2200 Fort Roots Drive, Bldg 58, North Little Rock, Arkansas 72114

\begin{abstract}
Objective: Potential moderator and mediator roles of several measures of socioeconomic status (SES) were investigated for the relationship between a family history of alcoholism (FH) and alcohol dependence symptoms in adulthood. Method: These analyses were performed with a sample of 931 men and 385 women participating in studies at the Alcohol Research Center, University of Michigan. Hierarchical multiple regression equations were used to assess whether SES mediated and moderated relationships between FH and alcohol dependence symptoms. Results: In general, measures of SES (education, occupation, personal and household income) were more important predictors of alcohol dependence symptoms among men, while FH was a stronger predictor among women. In the female sample, measures of personal and household
\end{abstract}

income interacted with family history such that the influence of family history on adult alcohol dependence symptoms was significantly stronger among low income women. Measures of SES and FH were additively related to alcohol dependence symptoms among men. Education partially meditated the relationship between family history and alcohol dependence symptoms among men, indicating that the influence of family history on subsequent alcohol problems among men may be partially due to familial alcoholism's negative effect on educational attainment. Conclusions: The results of this study suggest the influence of $\mathrm{FH}$ on alcohol dependence varies according to SES and gender, and point to the usefulness of examining potential moderators and mediators of family history of alcohol use disorders. (J. Stud. Alcohol 60: 825-832, 1999)
$\mathbf{T}$ THE OBSERVATION that alcoholism is more frequently found in some families than in others is not new (e.g., Blueler, 1955). Likewise, inverse relationships between socioeconomic status (SES) and alcoholism and alcohol-related problems have been consistently noted since the earliest epidemiological research (Park, 1983). Little work, however, has focused on the possible relationships between family history of alcoholism (FH) and SES. In this article, we attempt to bridge these studies as we investigate several SES indicators as potential moderators and mediators of FH's effect on alcohol dependence.

In general, the presence of alcoholic relatives in a pedigree increases the odds that the proband will develop alcoholism (Cotton, 1979; Merikangas, 1990). Further, increasingly dense FH appears to be associated with earlier age of onset,

Received: February 10, 1998. Revision: April 6, 1998.

*This work was supported by NIDA grant DA 07267-03 and NIAAA grants T32 AA07477 and P50AA 0738.

${ }$ Geoffrey M. Curran is also affiliated with the Department of Psychiatry, University of Arkansas for Medical Sciences, Little Rock, AR. When the research for this article was conducted he was at the Substance Abuse Research Center, University of Michigan, Ann Arbor. Scott F. Stoltenberg, Sharon A. Mudd, Frederic C. Blow and Robert A. Zucker are with the Department of Psychiatry and the Alcohol Research Center, University of Michigan. Elizabeth M. Hill is now affiliated with the Department of Psychology, University of Detroit-Mercy, Detroit, MI. more adverse consequences (e.g., social and legal) and more severe dependence (Turner et al., 1993). Additionally, those with alcoholic relatives have been found to differ from those without on myriad measures (e.g., cognitive performance [Drake et al., 1995], temperament and personality [Ohannessian and Hesselbrock, 1995] and response to alcohol [Schuckit et al., 1996]). Measures of FH provide an index of vulnerability; however, FH effects cannot be considered solely as genetic effects because, in families, genetic and environmental effects are inextricably confounded.

In terms of the SES/alcoholism relationship, recent largescale epidemiological studies have found inverse relations between measures of SES and alcohol use disorders. For example, the Epidemiological Catchment Area Study (Helzer et al., 1991) found higher lifetime prevalence of alcoholism among the less educated, and more frequent past year incidence of alcohol dependence among workers with lower occupational prestige. In addition, the National Comorbidity Study (Kessler et al., 1994) found inverse relationships between lifetime prevalence of substance use disorders (including alcohol) and measures of income and education. Although some research has linked higher SES to increased per capita consumption levels and other quantity-frequency measures (Hilton, 1991, Knupfer, 1989), the relationship between low SES and alcohol dependence and alcohol-related problems has been found to be almost universal (including 
the same studies linking higher SES with higher, but not intoxicating, levels of consumption).

As noted above, few studies have examined the associations between SES and FH. In the FH literature, however, many have recognized a potential relationship and have statistically controlled for SES (usually years of education) when examining the effects of FH on other measures. In more direct analyses regarding SES and FH, Hill et al. (1994, with an earlier subsample of data used in the present study) showed that alcohol dependence in adulthood was additively predicted by positive $\mathrm{FH}$ and childhood socioeconomic adversity. In research investigating mediators/moderators of FH, Sher et al. (1997) found a composite group of childhood stressors (e.g., parental abuse and neglect) to partially mediate the relationship between $\mathrm{FH}$ and offspring alcohol use disorder. Blackson (1995) found positive temperament and intellectual ability (higher IQ) to partially mediate the effects of a paternal history of substance abuse on the son's academic achievement. Further, Rogosch et al. (1990), while not investigating SES, found FH to be moderated by personality characteristics. Specifically, high levels of "dispositional self-awareness" buffered the relationship between FH and alcohol outcomes, while elevated "presumed personality risk" (e.g., impulsivity) magnified the effects of FH.

In light of the evidence described above linking SES and FH, coupled with the research demonstrating mediation/ moderation of the effects of FH by individual-level variables, and consistent with a developmental systems theory of onset and trajectory of alcoholism (Fitzgerald et al., 1995; Zucker et al., 1995), we hypothesized an interactive model of alcohol use disorders such that we expected the effects of FH to be magnified among those of lower SES. We also examined a mediated model in which the relationship between FH and subsequent alcohol use disorder may be at least partially explained by SES; that is, the influence of family history on subsequent alcohol use disorder may be partially indirect and felt through its negative influence on socioeconomic status.

\section{Method}

\section{Sample}

The study sample $(N=1316$; 931 men) consisted of subjects recruited for studies at the University of Michigan Alcohol Research Center (UMARC) during 1989-1997. The average (mean $[ \pm S D]$ ) age for men was $50.4 \pm 15.3$ years and the average age for women was $54.7 \pm 17.2$ years. The sample was primarily white- $86.5 \%$ of men and $90.5 \%$ of women; $10.3 \%$ of the male sample and $6.1 \%$ of the female sample were black, and $3.2 \%$ of men and $3.4 \%$ of women were of other racial/ethnic backgrounds. About half of the men in the sample were recruited from treatment sources $(47.7 \%)$, about half from the community $(45.8 \%)$, with the remainder from various other sources $(6.5 \%)$. Most women were recruited from the community $(67.0 \%)$, while others were recruited from treatment centers $(21.3 \%)$ and other sources $(11.7 \%)$.

\section{Recruitment and screening}

Participants were recruited from alcohol treatment centers and from the general population through advertising, direct mailings and word-of-mouth. After a brief screening interview, those who consented and were eligible for further studies were given the structured diagnostic interview analyzed herein. Patients from alcohol treatement centers were initially screened via chart review, which excluded subjects known to have psychiatric disorders that required treatment with medication, such as schizophrenia or manic depression. Participants resembled local county residents in education, race and marital status. Any potentially confounding effects of recruitment source on the associations of interest (e.g., gender differences) were controlled by using recruitment source as a covariate in statistical analyses.

\section{Measures}

Family history. Because measures of FH that provide information on family history density are generally superior to dichotomous measures at predicting diagnostically important alcohol use variables (Stoltenberg et al., 1998), we chose the variable "Degree." Degree is a four-level variable indicating either no first (parents/siblings) or second (aunts/uncles/ grandparents) degree alcoholic relatives $=0$, only second degree alcoholic relatives $=1$, only first degree alcoholic relatives $=2$, or both first and second degree alcoholic relatives $=3$. Thus, increasing Degree scores indicate greater family history density of alcoholism (Hill et al., 1994). Family history of alcoholism was assessed during interviews with the participant. Prior to 1995, a pedigree was constructed that showed children, parents, siblings, aunts, uncles and grandparents. Each relative was assigned a level of alcohol useabstinent, social drinker, probable or definite alcoholism. Alcoholism was coded using the criteria from the Family Informant Schedule and Criteria (FISC; Mannuzza et al., 1985). When the respondent could give examples of the relative being frequently drunk, drinking regularly and heavily, or "always had a glass in her/her hand," he or she was coded "probable alcoholic." If the respondent could also name specific consequences from the FISC list (legal, marital, work or health problems, fights when drunk, or alcoholism treatment), that relative was coded "definite alcoholic." In the present analysis "probable" and "definite" codes were collapsed. After 1995, FH assessment consisted of the screening portion of the Family History Assessment Module (FHAM; Rice et al., 1995). Participants were asked about problem drinking by their relatives (mother, father, brothers, sisters, sons, daughters, half-siblings, maternal grandparents, pater- 
nal grandparents, maternal siblings and paternal siblings) with the question: "Has drinking ever caused any of your relatives to have problems with health, family, their job or the police?" For each relative a "yes" was coded as "probable" alcoholic, a "no" response was coded as "not alcoholic."

The percentages of men $(n=931)$ and women $(n=385)$ falling into each Degree level were as follows: Degree 0$25.2 \%$ of men, $26.5 \%$ of women; Degree $1-27.1 \%$ of men, $28.3 \%$ of women; Degree 2-17.2\% of men, $21.6 \%$ of women; and Degree $3-30.5 \%$ of men, $23.6 \%$ of women.

Socioeconomic status. We chose four self-reported indicators of SES (Table 1). The first was a measure of educational attainment as measured by the highest grade completed in school. Second was a measure of occupational prestige based on the indexes for MSE12 census occupational categories (Stevens and Featherman, 1981). This scale ranges from 11-88, with the least prestigious occupations being household maids, textile operatives and bootblacks, and the highest being physicians, lawyers and dentists. Occupations not specifically coded in this reference were given averages of similar jobs. Homemakers were coded as the average of all occupations, which was 40 . Our last two indicators of SES, personal and household income, consisted of 17 categories that ranged from $\$ 0-1,999$ to $\$ 100,000$ or more.

Alcohol dependence symptoms. The Diagnostic Interview Schedule (DIS-III-R) was administered to all participants. This instrument is based on DSM-III-R criteria (American Psychiatric Association). We focused our analyses on a count of lifetime alcohol dependence symptoms (ADSX) ranging from 0 to 9 , and these data are reported in full. We also explored the models described below with dichotomous outcomes of alcohol dependence based on DSM-III-R (yes/no for dependence). While the measure of ADSX provided more precise information regarding the severity of alcohol dependence (i.e., number of symptoms), we wished to

TABLE 1. Sample sizes, means and standard deviations of alcohol dependence symptoms (ADSX) and SES variables in men and women

\begin{tabular}{|c|c|c|c|c|}
\hline & \multicolumn{2}{|r|}{ Men } & \multicolumn{2}{|r|}{ Women } \\
\hline & $n$ & Mean $( \pm S D)$ & $n$ & Mean $( \pm$ SD) \\
\hline ADSX & 923 & $4.63 \pm 3.42$ & 377 & $2.88 \pm 3.23$ \\
\hline Years of education & 927 & $13.95 \pm 2.59$ & 385 & $14.26 \pm 2.41$ \\
\hline Occupation index ${ }^{a}$ & 920 & $43.08 \pm 22.88$ & 384 & $45.59 \pm 17.25$ \\
\hline Personal income ${ }^{b}$ & 916 & $7.91 \pm 3.16$ & 366 & $7.05 \pm 3.00$ \\
\hline Household income ${ }^{c}$ & 846 & $8.99 \pm 3.03$ & 327 & $9.35 \pm 2.45$ \\
\hline
\end{tabular}

${ }^{a}$ Occupational status is based on Stevens and Featherman (1981). This scale ranges from 11-88, with the least prestigious occupations being household maids and textile operatives and the most prestigious being physicians and lawyers.

${ }^{b}$ Mean personal income for men was approximately $\$ 15,000$, with a standard deviation ranging from $\$ 5,000$ to $\$ 49,000$. Mean personal income for women was approximately $\$ 12,000$, with a standard deviation ranging from $\$ 4,000$ to $\$ 39,000$.

cMean household income for men was approximately $\$ 20,000$, with a standard deviation ranging from $\$ 5,000$ to $\$ 49,000$. Mean household income for women was approximately $\$ 23,000$, with a standard deviation ranging from $\$ 7,000$ to $\$ 49,000$ see if our results with the continuous dependent measures were replicated with a more diagnostic categorization of dependence (yes/no). Results from these accompanying analyses are presented as they relate the findings derived with the continuous outcomes (ADSX).

\section{Statistical analyses}

Following the recommendations of Baron and Kenny (1986) we developed moderated and mediated models of the relationship between FH, SES and ADSX. We investigated potential gender differences by splitting the sample and performing the analyses separately for men and women. Further, given the evidence that SES measures such as education and occupation have been shown to differ in their impact on psychological distress and substance abuse (Curran and Zucker, submitted for publication; Liberatos et al., 1988) we analyzed each SES measure separately; i.e., repeating the series of regressions, including one SES measure at a time.

In the moderated models, we performed hierarchical multiple regression with the following variables included in step 1: the measure of family history (Degree), a measure of SES (either education, occupation, personal or household income), age and a variable indicating the subject's recruitment source (i.e., treatment or community). In a second step, a product term (Degree $\times$ SES measure) was entered. Following the recommendation of Jaccard et al. (1990), all variables used in the creation of the product terms were centered prior to analysis. If the interaction was significant, we performed an $F$ test to gauge the significance of the increase in $R^{2}$ (see Jaccard et al., 1990, p. 18). If a gender difference was found in these analyses such that an interaction was found in one gender but not the other, this difference was statistically verified in a model using the whole sample with a three-way interaction specified as follows$\mathrm{SES} \times \mathrm{FH} \times$ Gender. Following the recommendations of Aiken and West (1991), all first and second order terms implicated by the three-way interaction were included in the unitary sample models (i.e., gender, SES, FH, SES $\times$ FH, SES $\times$ Gender and $\mathrm{FH} \times$ Gender). If the three-way interaction was significant, then the gender difference observed in the split sample analyses reached statistical significance.

As discussed in the introduction, we hypothesized that SES was the moderator. Therefore, we expected the influence of FH on ADSX to vary by SES. Interestingly, the choice of moderator is solely theoretical, as the creation of the product term is the same methodologically-variable $Y \times$ variable $Z$ (Jaccard et al., 1990). The import of the "which is the moderator?" question comes when assigning values of the independent and moderator variables in determining the simple slopes; i.e., the coefficients of the independent variable (FH in our case) on the dependent variable (ADSX) at the low/high values of the moderator (SES in our case). It is possible to model the interaction the opposite way, 
such that the effect of SES varies by FH status. However, this was not our hypothesis.

While many depict interactions by graphing simple slopes (Aiken and West, 1991; Jaccard et al., 1990), we chose to graph the mean levels of our dependent variable (ADSX) at each level of the independent variable (FH) by high and low SES groups (median split). In this way, changes in alcohol dependent symptoms can be observed across each category of family history, while the graphing of simple slopes provides a line with only one slope, thereby blurring the differences across family history loadings. We did, however, generate simple slopes for low and high socioeconomic status, and they are discussed below.

In our mediated models we investigated whether the influence of FH on ADSX was mediated by SES; i.e., we explored the possibility that FH's influence on ADSX was indirect and felt through its negative influence on SES. Our choice of SES as potential mediator of FH was a theoretical one based on our understanding of the constructs and their temporal order; i.e., the experience of familial alcoholism (among subjects' parents/grandparents) usually preceding subjects' adult attainment of socioeconomic status. We tested for mediation in a series of regressions as follows: we first regressed the SES measure on Degree; next we regressed the ADSX measure on Degree; third, we regressed ADSX on Degree and SES. Each regression equation can be considered a criterion for mediation such that Degree must predict SES (first equation) and ADSX (second equation) and its coefficient must be significantly reduced (partial mediation) or rendered nonsignificant (complete mediation) with the inclusion of SES in the model predicting ADSX (third equation). All three critera must be met to show evidence of mediation (see Baron and Kenny, 1986, p. 1177, for a more detailed explanation of mediated models). As in the moderated models, we controlled for age and recruitment source in each equation. As described above, we also performed these moderated and mediated models with logistic regression using a dichotomous measure of alcohol dependence (yes/no).

\section{Results}

\section{Moderator models}

In the main effects analyses for men, all the SES measures were significant negative predictors of ADSX, with the occupation and education measures producing the larger standardized betas (occupation $=-.24$, education $=-.21$, household income $=-.12$, personal income $=-.08$ ). Degree was consistently significant and positive, with a mean beta weight of .08. As expected by its definition, the recruitment source variable was consistently the strongest predictor (beta $=.53$ ). Age never reached statistical significance. The adjusted $R^{2}$ for each model was: with occupation $=.44$, with education $=.43$, with household income $=.40$, with personal income $=.40$. None of the four SES $\times$ Degree interactions was significant, indicating that, among men, SES and FH are additively related to ADSX. As well, the SES measures were consistently stronger predictors, among men, than the FH measure.

A different picture emerged in the female sample. While the recruitment source variable was also the strongest predictor and age was also consistently nonsignificant, the only SES measure to reach significance in the main effects analyses was education (standardized beta $=-.12$ ). Further, Degree (significant in all analyses) averaged a larger beta weight for women (average beta $=.13$ ) as compared to men (average beta $=.08)$. For women, FH was a stronger predictor of ADSX than SES, whereas for men the opposite was true.

In the female sample, two interactions were found-both personal and household income measures interacted with Degree such that the impact of FH was greater among lower income women. See Table 2 for the regression model involving household income. The model with personal income is not shown due to its similar results. As depicted in Figure 1 (again, only household income is shown), lower income women show higher average numbers of alcohol dependence symptoms for family history categories 1-3, but not for category 0 (i.e., no family history). While both groups of women show an increase among these categories, the lower income women experience a higher rate of increase, as is shown by an examination of the simple slopes. The slope of FH on ADSX for women with low household income is .81 , while the slope for high income women is .11. (For the generation of the simple slopes, we dichotomized the income measures into "low" or "high" based on one standard deviation below and above the mean.) Likewise, the slope of $\mathrm{FH}$ on ADSX for women with low personal income is .75, while the slope is .16 for women with high personal income. Again, these simple slopes indicate that the effect of FH on ADSX is stronger for low income women. In analyses with a unitary sample and three-way interactions specified, the Household Income $\times \mathrm{FH} \times$ Gender interaction was significant at $p<.05$, while the Personal Income $\times \mathrm{FH} \times$ Gender interaction achieved a $p$ value of .1. These analyses indicate that only the gender difference in the Household Income $\times \mathrm{FH}$ interaction reached statistical significance.

TABLE 2. Main and significant interaction effects for women (dependent variable $=$ number of alcohol dependent symptoms, moderator $=$ household income)

\begin{tabular}{llrc}
\hline Predictor variables & $R^{2}$ & \multicolumn{1}{c}{$\mathrm{b}$} & \multicolumn{1}{c}{$\beta$} \\
\hline Step 1 & $.39^{\ddagger}$ & & \\
Household income & & -0.06 & -0.05 \\
Family history & & 0.40 & $0.14^{\dagger}$ \\
Age & & -0.01 & -0.04 \\
Community/TX & & 4.87 & $0.60^{\ddagger}$ \\
Step 2 & $.01^{*}\left(\Delta R^{2}\right)$ & & $-0.12^{\dagger}$ \\
FH $\times$ HI & & -0.14 & -0.12 \\
\hline
\end{tabular}

Note: $n=318 ; \quad \mathrm{TX}=$ treatment; $\mathrm{FH}=$ family history; $\mathrm{HI}=$ household income.

${ }^{*} p<.05 ;{ }^{\dagger} p<.01 ;{ }^{\ddagger} p<.001$. 


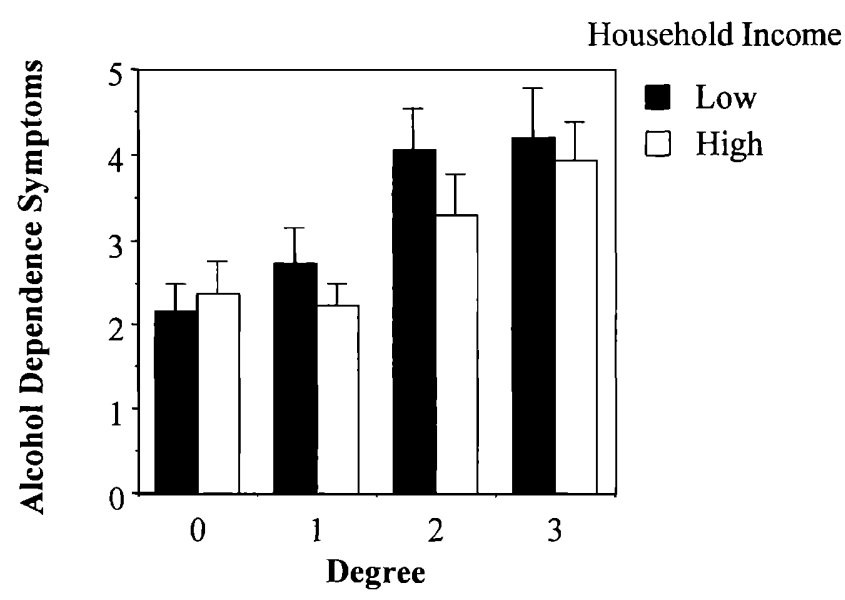

FIGURE 1. Number of alcohol dependence symptoms for women with low and high household incomes across FH categories that increase in "density" from $0-3$

In terms of the analyses with the dichotomous measure of dependence, the patterns of direct effects were very similar. In one difference, the $\mathrm{FH} /$ household income interaction among women was not replicated; however, the FH/personal income interaction in the female sample was. The similarities are not surprising given the .86 point-biserial correlation between our dichotomous measure of dependence (yes/no) and number of dependence symptoms (ADSX).

\section{Mediated models}

In the male sample, Degree significantly predicted each SES measure and the measure of ADSX, thereby meeting the first two of the three criteria necessary for mediation. However, only education met the third criterion (see Table 3 ). With the inclusion of the measure of education in the third equation, the regression coefficient of Degree was reduced from .29 to .18 (the reductions with the other SES variables were .06 for occupation, .01 for personal income and .04 for household income). This reduction in the coefficient indicates that, among men the influence of FH on ADSX may be

TABLE 3. Mediated relationship between family history and socioeconomic status for men (dependent variable $=$ number of alcohol dependence symptoms)

\begin{tabular}{llll}
\hline Predictor variables & $R^{2}$ & b & $\beta$ \\
\hline Equation $2^{a}$ & $.39 \ddagger$ & & \\
$\quad$ Family history & & 0.29 & $0.10^{\ddagger}$ \\
Age & & 0.00 & 0.00 \\
Community/TX & & 4.14 & $0.61^{\ddagger}$ \\
Equation 3 & $.43^{\ddagger}$ & & \\
Family history & & 0.18 & $0.06^{*}$ \\
Education & & -0.28 & $-0.21^{\ddagger}$ \\
Age & 0.00 & 0.00 \\
Community/TX & & 3.50 & $0.51^{\ddagger}$ \\
\hline
\end{tabular}

Note: $n=918$. TX $=$ treatment. ${ }^{a}$ Equation 1, where Degree significantly predicts education, is not depicted.

${ }^{*} p<.05 ;{ }^{\ddagger} p<.001$. partially mediated by educational attainment. In other words, familial alcoholism, while exerting a direct effect on subsequent alcohol use disorder, may also indirectly affect drinking levels by lowering men's educational attainment.

Baron and Kenny (1986) state that mediated models should look for a "significantly reduced" relationship between the independent and dependent variables with the inclusion of the mediator, but include no definition or example of what a significant reduction is. In a review of statistics texts we could not find a general rule for what size/percent change in the beta is large enough to constitute "true mediation," so we developed our own. Among men, the education measure created the largest reduction in the effect of family history and was the only variable to reduce the family history measure by over one third. To remain conservative in our interpretation, we concluded that education had the only notable or substantial mediating effect.

We observed no strong evidence of SES mediating the effects of FH on alcohol dependence among women. First, Degree did not significantly predict occupation and household income, so the first condition of mediation for these variables was not met. With regard to education and personal income, neither substantially decreased the coefficient of Degree when included in the model (education decreased the coefficient by .04 and personal income caused no decrease). Again, these results indicate that, for women, the influence of family history on subsequent alcohol use disorder is not likely to be significantly mediated by SES.

The results from the mediated analyses with the dichotomous measures of alcohol dependence were very similar to those from the continuous measure analyses: no evidence of mediation among women and education mediating the effect of FH among men. In one difference, however, FH was also partially mediated by occupational status among men (approximately a $32 \%$ drop in beta weight). We are unsure if this additional finding is attributable to the substantive difference between the dependent measures (i.e., one being more sensitive to dependence severity and one being a strict dichotomous characterization) or the psychometric difference. At present, however, we remain more confident in the findings from the analyses with the continuous dependent measure until it is demonstrated in future research that a dichotomous measure of alcohol dependence is more appropriate for such analysis.

\section{Discussion}

Our findings suggest the presence of gender differences in the ways in which socioeconomic status and a family history of alcoholism influence alcohol dependence. In the main effects analyses FH emerged as a significant predictor among both genders; however, our data suggest its influence is more salient among women. This finding is not consistent with findings from twin and adoption studies in which the inherited contribution to alcoholism in women appears to be equal 
to (Heath et al., 1997a; Kendler et al., 1995) or less than that in men (McGue and Slutske, 1996). Our results do support the findings of Crum and Harris (1996) in that the association between alcohol use disorders and parental history of heavy drinking was stronger in women than in men. Of course, measures of FH are not pure measures of genetic influence because, in a family, genes and environment are confounded. Perhaps women are more sensitive to the family environment than men; however, we are unable to address this issue in the present study. The FH measure showed larger regression coefficients in the female sample, and with the presence of interactions with income measures, our data suggest that $\mathrm{FH}$ is strengthened as a predictor of subsequent alcohol dependence symptomology among low income women. No SES/family history interactions were found in the male sample, indicating that FH and SES are additively related to alcohol dependence symptoms in men.

Each SES measure in the main effects analyses (especially education and occupation) was significantly related to alcohol dependence symptoms among men; only education was a significant predictor among women. These findings may be reflecting gender differences in the meaning and impact of SES. Such confounding factors as marriage, the larger presence of women in part-time work, and greater downward mobility often faced by women after divorce (Beeghley, 1996) may render SES indicators among women, especially income and occupation, less reliable as predictors of statusrelated behaviors such as alcohol use disorders. Women's educational attainment is the SES measure least tied to a partner's status and provides perhaps the clearest linkage for women between status differences and alcohol use disorders. Kessler (1982) found education to be the SES measure most associated with women's mental health status. Data from Liberatos et al. (1988) and Winkleby et al. (1992) suggest that education may be the SES measure most related to health outcomes because of its association with many lifestyle characteristics and health-related behaviors. This may be especially true for women. Clearly, the association between gender and SES in predicting health outcomes deserves greater study. In general, our findings support other research indicating SES as a more important predictor of alcohol use problems for men than for women (see Helzer et al., 1991). However, numerous studies have found lower SES to be related, if weakly, to problematic drinking and alcohol dependence in women (Helzer et al., 1991; Herd and Grube, 1993; Knupfer, 1989; Parker and Harford, 1992). Interestingly, in our sample, income appears to influence women's alcohol dependence only in its interaction with FH. These results may indicate that, for women, income alone is not a strong predictor of alcohol use disorders, but is "activated" in the presence of other predisposing factors. Alternatively, it may be that high income offers some protection from the effects that dense family history has on problem alcohol use. Future studies could be focused on identifying the salient features associated with the interaction between income and family history of alcoholism in women.

Our finding of education (and occupation in the logistic analyses) partially mediating $\mathrm{FH}$ among men suggests the possibility that family history of alcoholism exerts its influence partly through its effect on more macrolevel social processes. In both our male and female samples the FH measure predicted lower educational attainment, supporting the findings of Heath et al. (1997b). The hierarchical inclusion of SES in measurement models (both male and female) with FH reduced the size of family history's effect on alcohol dependence symptoms. Among women the reduction was slight and we considered it too small for inclusion as true "mediation," but among men the decrease was more substantial.

Our study involved a relatively narrow set of predictors and was limited to one criterion of alcohol dependence symptoms; therefore, it should be considered preliminary in nature. No previous research, to our knowledge, had investigated the potential moderating and mediating roles of SES in the relationship between family history and alcohol use disorders, and we approached the study in an exploratory manner. Other limitations include representativeness problems associated with our nonrandom sample composed of alcohol treatment- and community-derived subjects and the measurement error inherent in self-reports. Measurement error is especially problematic when investigating interaction effects because the error is multiplied in the creation of the interaction terms (Busemeyer and Jones, 1983; Curran et al., 1997). Three-way terms are thus more greatly affected than twoway terms. This problem can lead to Type II error in the estimation of parameters and in tests of significance, and may be related to the fact that relatively few of the interactions tested were significant. In another limitation, our data are cross-sectional, and it is possible that the SES-alcohol dependence relationships we are describing are the reverse; that is, alcohol dependence may be driving persons into lower SES. It is likely that SES and alcohol dependence have a reciprocal relationship to some extent. Indeed, while some data indicate that alcohol problems can negatively influence job status and income (Mullahy and Sindelar, 1993), a larger body of evidence finds indicators of SES to predict alcohol and other substance problems longitudinally (Curran and Zucker, under review).

In light of these limitations, our findings, along with those of Rogosch et al. (1990), suggest that family history of alcoholism is not a strictly deterministic influence on offspring alcohol problems. Rather, this predisposition appears to, at least in part, indirectly influence alcoholism through social means, and it does not influence people equally regardless of other factors, such as gender or socioeconomic status (present study) or personality (Rogosch et al., 1990). In family history studies such as this, however, biological and social influences are intertwined such that we are unable to distinguish their "true" independent effects; yet through such work 
we recognize both to be important. Our research suggests that greater effort should be made in future work to identify moderators and mediators of family history effects on subsequent alcoholism. Indeed, research into the interrelation of psychological, social and biological variables is crucial to our understanding of the etiology of alcohol use disorders.

\section{Acknowledgements}

The authors wish to thank Jill A. Curran, Russell P.D. Burton and two anonymous reviewers for their comments on earlier drafts of this article.

\section{References}

AIKEN, L.S. AND WeSt, S.G. Multiple Regression: Testing and Interpreting Interactions, Thousand Oaks, CA: Sage Pubns., Inc., 1991.

BARON, R.M. AND KENNY, D.A. The moderator-mediator variable distinction in social psychological research: Conceptual, strategic, and statistical considerations. J. Pers. Social Psychol. 51: 1173-1182, 1986.

BeEghley, L. The Structure of Social Stratification in the United States, Newton, MA: Allyn and Bacon, Inc., 1996.

BLACKSON, T.C. Temperament and IQ mediate the effects of family history of substance abuse and family dysfunction on academic achievement. J. Clin. Psychol. 51: 113-122, 1995.

BLEULER, M. Familial and personal background of chronic alcoholics. In: Diethelm, O. (Ed.) Etiology of Chronic Alcoholism, Springfield, IL: Charles C Thomas, Pub., 1955, pp. 110-166.

BuSEMEYER, J.R. AND JoNEs, L.E. Analysis of multiplicative combination rules when the causal variables are measured with error. Psychol. Bull. 93: $549-562,1983$

Cotton, N.S. The familial incidence of alcoholism: A review. J. Stud. Alcohol 40: 89-116, 1979.

Crum, R.M. aND HaRris, E.L. Risk of alcoholism and parental history: Gender differences and a possible reporting bias. Genet. Epidemiol. 13: 329-341, 1996.

Curran, G.M., White, H.R. and Hansell, S. Predicting problem drinking: A test of an interactive social learning model. Alcsm Clin. Exp. Res. 21: 1379-1390, 1997.

CURRAN, G.M. AND ZuCKer, R.A. Socioeconomic status and health: Relationships among SES and substance abuse, other psychopathology, and physical well-being, submitted for publication.

Drake, A.I., Butters, N., Shear, P.K., Smith, R.T., Bondi, M., Irwin, M. AND SchucKit, M.A. Cognitive recovery with abstinence and its relationship to family history for alcoholism. J. Stud. Alcohol 56: 104-109, 1995.

FitzGerald, H.E., ZuCKer, R.A. AND YANG, H.-Y. Developmental systems theory and alcoholism: Analyzing patterns of variation in high-risk families. Psychol. Addict. Behav. 9: 8-22, 1995.

Heath, A.C., Bucholz, K.K., Madden, P.A.F., Dinwiddie, S.H., Slutske, W.S., Bierut, L.J., STatham, D.J., DunNe, M.P., WhitFIELD, J.B. AND MARTIN, N.G. Genetic and environmental contributions to alcohol dependence risk in a national twin sample: Consistency of findings in women and men. Psychol. Med. 27: 1381-1396, 1997a.

Heath, A.C., True, W.R., Bucholz, K.K., Reich, W., Slutske, W.S., Eisen, S.A., Romeis, J.C., Waterman, B., Scherrer, J.F., GoldBERG, J., Lyons, M.J. and Tsuang, M.T. Economic costs of alcoholism: Long-term impact on family income. Alcsm Exp. Clin. Res. 21: 137A, 1997b.

Helzer, J.E., Burnam, A. AND McEvoy, L.T. Acohol abuse and dependence. In: RoBins, L.N. AND Regier, D.A. (Eds.) Psychiatric Disorders in America: The Epidemiologic Catchment Area Study, New York: Free Press, 1991, pp. 81-115.
HeRD, D. AND GruBE, J. Drinking contexts and drinking problems among black and white women. Addiction 88: 1101-1110, 1993.

HiLl, E.M., BLow, F.C., YounG, J.P AND Singer, K.M. Family history of alcoholism and childhood adversity: Joint effects on alcohol consumption and dependence. Alcsm Clin. Exp. Res. 18: 1083-1090, 1994.

HILTON, M.E. The demographic distribution of drinking patterns in 1984. In: Clark, W.B. and Hilton, M.E. (Eds.) Alcohol in America: Drinking Practices and Problems, Albany, NY: State Univ. of New York Press, 1991, pp. 73-86.

JacCard, J., Turrisi, R. and WaN, C.K. Interaction Effects in Multiple Regression, Thousand Oaks, CA: Sage Pubns., Inc., 1990.

Kendler, K.S., Walters, E.E., Neale, M.C., Kessler, R.C., Heath, A.C. AND EAVES, L.J. The structure of the genetic and environmental risk factors for six major psychiatric disorders in women: Phobia, generalized anxiety disorder, panic disorder, bulimia, major depression and alcoholism. Arch. Gen. Psychiat. 52: 374-383, 1995.

KesSLER, R.C. A disaggregation of the relationship between socioeconomic status and psychological distress. Amer. Sociol. Rev. 47: 752$764,1982$.

Kessler, R.C., McGonagle, K.A., Zhao, S., Nelson, C.B., Hughes, M., Eshleman, S., Wittchen, H.-U. and Kendler, K.S. Lifetime and 12-month prevalence of DSM-III-R psychiatric disorders in the United States. Arch. Gen. Psychiat. 51: 8-19, 1994.

KNUPFER, G. The prevalence in various social groups of eight different drinking patterns, from abstaining to frequent drunkenness: Analysis of 10 U.S. surveys combined. Brit. J. Addict. 84: 1305-1318, 1989.

Liberatos, P., LinK, B.G. AND Kelsey, J.L. The measurement of social class in epidemiology. Epidemiol. Rev. 10: 87-121, 1988.

MCGUE, M. AND SLUTSKE, W. The inheritance of alcoholism in women. In: Howard, J.M., Martin, S.E., MaIl, P.D., Hilton, M.E. and Taylor, E.D. (Eds.) Women and Alcohol: Issues for Prevention Research. NIAAA Research Monograph No. 32, NIH Publication No. 96-3817, Washington: Government Printing Office, 1996, pp. 65-91.

Mannuzza, S., Fyer, A.J., ENDicotT, J. AND KLIEN, D.F. Family Informant Schedule and Criteria (FISC), New York: New York Anxiety Disorders Clinic, New York State Psychiatric Institute, 1985.

Merikangas, K.R. The genetic epidemiology of alcoholism. Psychol. Med. 20: 11-22, 1990.

MullahY, J. and SindelaR, J.L. Alcoholism, work, and income. J. Labor Econ. 11: 494-520, 1993

Ohannessian, C.M. AND Hesselbrock, V.M. Temperament and personality typologies in adult offspring of alcoholics. J. Stud. Alcohol 56: 318-327, 1995.

Park, P. Social-class factors in alcoholism. In: Kissin, B. AND BegleITER, H. (Eds.) The Biology of Alcoholism, Vol. 6: The Pathogenesis of Alcoholism: Psychosocial Factors, New York: Plenum Press, 1983, pp. 365-404.

Parker, D.A. And Harford, T.C. The epidemiology of alcohol consumption and dependence across occupations in the United States. Alcohol Hlth Res. World 16: 97-105, 1992.

Rice, J.P., Reich, T., Bucholz, K.K., Neuman, R.J., Fishman, R., RoChBERG, N., HESSElbrock, V.M., NURNBERGER, J.I., JR., SCHUCKIT, M.A. AND Begleiter, $H$. Comparison of direct interview and family history diagnosis of alcohol dependence. Alcsm Clin. Exp. Res. 19: 1018-1023, 1995

Rogosch, R., Chassin L. and Sher, K.J. Personality variables as mediators and moderators of family history risk for alcoholism: Conceptual and methodological issues. J. Stud. Alcohol 51: 310-318, 1990.

Schuckit, M.A., Tsuang, J.W., ANTHENELli, R.M., TipP, J.E. AND NuRNBERGER, J.I. Alcohol challenges in young men from alcohol pedigrees and control families: A report from the COGA project. J. Stud. Alcohol 57: 368-377, 1996.

Sher, K.J., Gershuny, B.S., Peterson, L. and Raskin, G. The role of childhood stressors in the intergenerational transmission of alcohol use disorders. J. Stud. Alcohol 58: 414-427, 1997. 
Stevens, G. and Featherman, D.L. A revised socioeconomic index of occupational status. Social Sci. Res. 10: 364-395, 1981.

STOltenberg, S.F., Mudd, S.A. Blow, F.C. ANd Hill, E.M. Evaluating measures of family history of alcoholism: Density versus dichotomy. Addiction: 93: 1511-1520, 1998.

Turner, W.M., Cutter, H.S.G., Worobec, T.G., O'Farrell, T.J., BAYOG, R.D. AND TsuANG, M.T. Family history models of alcoholism: Age of onset, consequences and dependence. J. Stud. Alcohol 54: 164-171, 1993.
Winkleby, M.A., Jatulis, D.E., Frank, E. and Fortmann, S.P. Socioeconomic status and health: How education, income, and occupation contribute to risk factors for cardiovascular disease. Amer. J. Publ. Hlth 82: 816-820, 1992.

ZuCKER, R.A., FitZGERALD, H.E. AND Moses, H.D. Emergence of alcohol problems and the several alcoholisms: A developmental perspective on etiologic theory and life course trajectory. In: CICCHETTI, D. AND COHEN, D.J. (Eds.) Developmental Psychopathology, Vol. 2: Risk, Disorder, and Adaptation, New York: John Wiley \& Sons, Inc., 1995, pp. 677-711. 